УДК 336

\author{
Бабаева Айида Эдуардовна, Тер-Григорьянц Анна Александровна
}

\title{
ПРОБЛЕМЫ И ПЕРСПЕКТИВЫ РАЗВИТИЯ СИСТЕМЫ ГОСУДАРСТВЕННОГО ФИНАНСОВОГО КОНТРОЛЯ В РОССИЙСКОЙ ФЕДЕРАЦИИ
}

В статье выделены и систематизированы особенности функционирования системы государственного финансового контроля России исходя из организачионных, правовых, экономических и методических аспектов ее формирования. Приводится оценка эффективности исполнения государственных программ на основании отчётных материалов Счетной палаты РФ по итогам внеинего аудита за 2017 год. По результатам исследования идентифицированы и сформулированы проблемы и направления развития отечественной системы государственного финансового контроля, а также предложен ряд мероприятий в рамках вектора его развития на среднесрочную перспективу. Построенная модель комиуникационного взаимодействия финансовых контрольных органов РФ позволит рецить имеюииеся затруднения в части информационного и коммуникационного обеспечения деятельности субъектов государственного финансового контроля.

Ключевые слова: государственный финансовый контроль, государственная программа, модель, перспективы развития, коммуникационное взаимодействие, нормативно-правовая база, эффективность.

\section{Ayida Babaeva, Anna Ter-Grigoryants \\ PROBLEMS AND PROSPECTS OF DEVELOPMENT OF THE SYSTEM OF PUBLIC FINANCIAL CONTROL IN THE RUSSIAN FEDERATION}

The article highlighted and systematized the features of the functioning of the system of state financial control of Russia based on the organizational, legal, economic and methodological aspects of its formation. An assessment is made of the effectiveness of the implementation of state programs on the basis of reporting materials of the Accounts Chamber of the Russian Federation following the results of an external audit for 2017. According to the results of the study, problems and directions of development of the national system of state financial control were identified and formulated, and a number of measures were proposed within the framework of its development vector for the medium term. The constructed model of communication interaction of financial control bodies of the Russian Federation will allow to solve the existing difficulties in terms of information and communication support of the activities of the subjects of state financial control.

Key words: state financial control, state program, model, development prospects, communication interaction, regulatory framework, éfficiency.

Bведение / Introduction. Эффективность использования государственных финансов напрямую зависит от качества реализации управленческих функций со стороны государственных контрольных и распорядительных органов. При этом контроль в системе государственного управления в силу разновидностей его осуществления является связующим элементом между настоящим и последующим циклами процесса управления финансами.

Государственный финансовый контроль в отечественной практике представляет собой совокупность действий и операций по проверке соблюдения органами государственной власти и местного самоуправления финансового законодательства Российской Федерации, рациональности и эффективности использования государственных финансов и материальных ресурсов [3]. Следовательно, основной целью функционирования системы государственного финансового контроля является обеспечение законности и эффективности использования государственных и муниципальных финансовых ресурсов. 
В России финансовый контроль осуществляется в двух направлениях: внешний государственный финансовый контроль, реализуемый Счетной палатой РФ, и внутренний, который проводится Федеральным казначейством РФ. При этом организационно-правовая зависимость внутри системы государственного финансового контроля, как и структурная взаимосвязь между ее субъектами, не регламентированы бюджетным законодательством, что нарушает целость функционирования данного финансово-правового института в современном обществе.

Maтериаль и методы / Materials and methods. В процессе исследования нами использовались труды отечественных исследователей и практических деятелей в сфере государственного финансового контроля, в частности таких авторов, как Э. А. Исаев, П. С. Шевченко, А. Ю. Юльин, С. О. Шохин, А. Ю. Мигачева, Е. В. Овчарова, К. А. Зылевич, Ю. В. Прохоров, а также законодательные акты в части регулирования деятельности органов государственного финансового контроля в стране области предмета исследования.

Исследование базируется на использовании системного подхода к изучаемому объекту. В процессе рассмотрения и исследования системы государственного финансового контроля РФ применялись общенаучные методы теоретического познания: методы статистического и логического анализа и синтеза, сравнения, дедукции и обобщения, технологии структурного и графического моделирования. Каждый из методов применялся адекватно его функциональным возможностям, что позволило обеспечить аргументированность и достоверность обобщений, выводов и положений, полученных в работе.

Результаты и обсуждение / Results and discussion. По результатам внешнего государственного аудита, проведенного Счетной палатой РФ, по итогам 2017 г. выявлено, что из 40 госпрограмм федерального бюджета со средним уровнем эффективности исполнено лишь 20 , на низком уровне -8 , еще 11 госпрограмм не подлежат оценке эффективности, рис. 1 [1]. При этом только 9 программ осуществляются в соответствии со своими целями и задачами и соответствуют документам стратегического планирования.

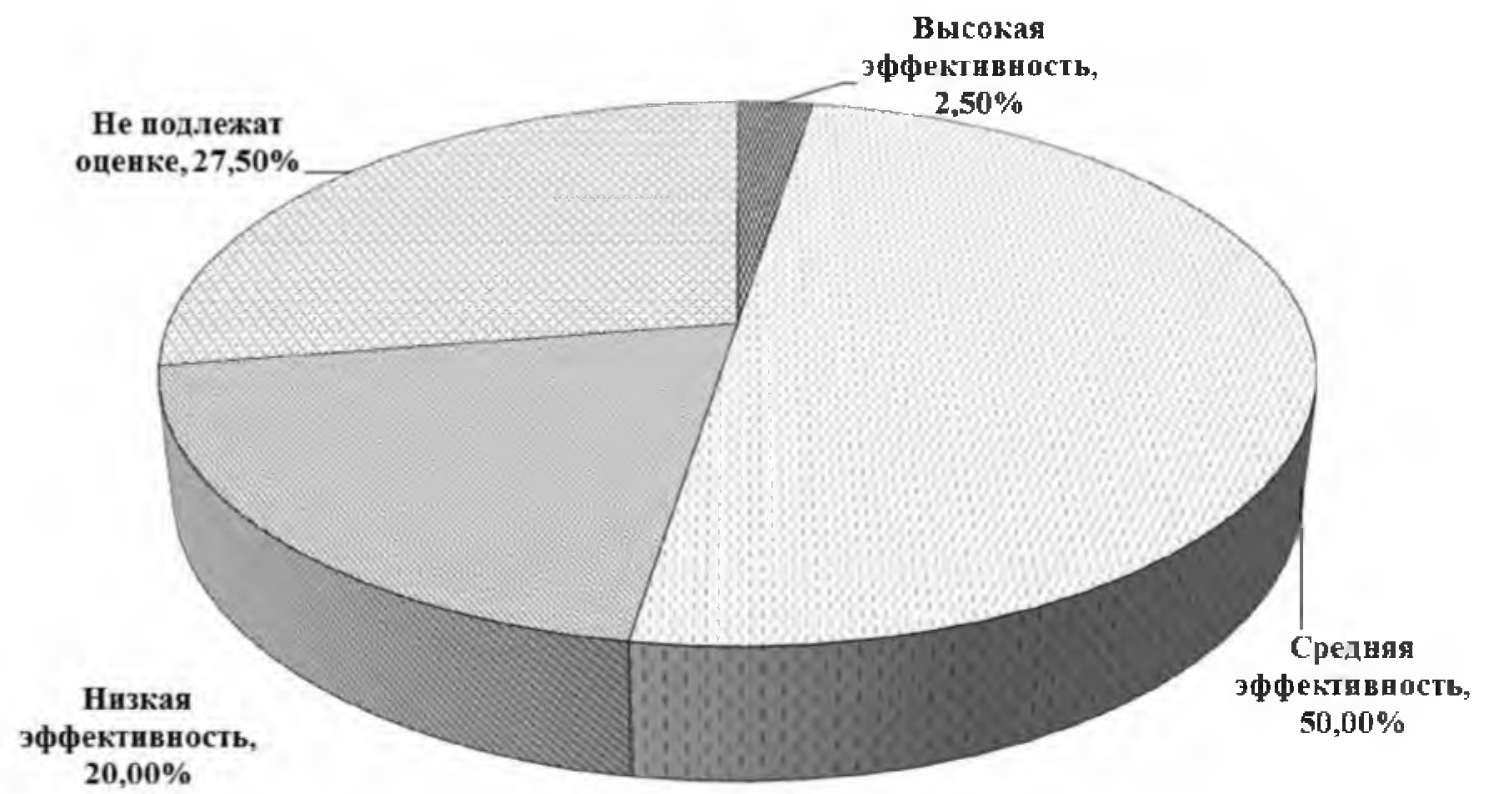

Рис. 1. Показатели эффективности исполнения госпрограмм федерального бюджета в 2017 году (по результатам внешнего государственного аудита Счетной палатой РФ) 
Следует отметить, что на финансирование всех госпрограмм из федерального бюджета использовано 8 трлн руб., что составляет $60 \%$ всех расходов бюджета, в то время как реализовано всего $22,5 \%$ запланированного объема программ [4]. Полученные результаты явно свидетельствуют о наличии серьезных проблем в функционировании системы бюджетного распределения средств и государственного финансового контроля (далее - ГФК) в стране.

Изучив условия и результаты работы органов ГФК за 2015-2017 гг. в финансово-бюджетной сфере с учетом правового обеспечения деятельности контрольных структур считаем возможным идентифицировать и выделить 4 группы проблем, связанных с функционированием самой системы финансового контроля РФ (рис. 2).

Вместе с тем внедрение цифровой экономики в бюджетную сферу определяет новые требования к системе государственного финансового контроля, а, следовательно, и обозначает новые пути ее развития [5].

\begin{tabular}{|c|c|}
\hline Организационные & Mpasosble \\
\hline 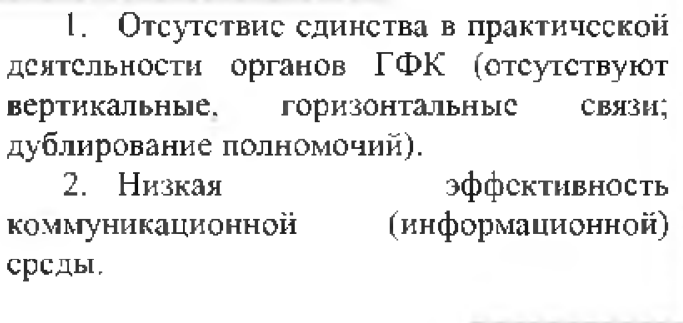 & $\begin{array}{l}\text { 1. Нссовсршснство нормативно-правовой } \\
\text { базы, рсгламснтирующсй дсятльность } \\
\text { Фсдерального казначейства на федсральном } \\
\text { уровне. } \\
\text { 2. Отсутствие ключевых аспектов } \\
\text { государствснного аудита в } 33 \text { «Об } \\
\text { ауднторской деятсльностия от } 30.12 .2018 \text { № } \\
\text { 307-Ф3 }\end{array}$ \\
\hline $\begin{array}{r}\text { Актуальнь } \\
\text { функцио } \\
\text { систем }\end{array}$ & $\begin{array}{l}\text { е проблемы } \\
\text { ирования } \\
\text { ы ГФК }\end{array}$ \\
\hline $\begin{array}{l}\text { 1. Высокис финансовыс затраты на } \\
\text { организацню и осуществленнс контрольных } \\
\text { мсроприятий. }\end{array}$ & $\begin{array}{l}\text { 1. Отсутствис } \\
\text { мстодологичсского ибновлснного } \\
\text { провсденис комп.тексного внсшснтария дия }\end{array}$ \\
\hline Экономические & Мешодологические \\
\hline
\end{tabular}

Рис. 2. Актуальные проблемы функционирования системы государственного финансового контроля в РФ

Таким образом, учитывая отмеченные проблемы, а также основные позиции стратегии контрольно-ревизионных органов, выделим первоочередные направления развития системы ГФК в среднесрочной перспективе (рис. 3).

Основными мероприятиями, позволяющими реализовать сформулированные направления совершенствования системы ГФК в стране, являются:

- совершенствование нормативно-правовой базы функционирования органов внешнего и внутреннего финансового контроля в части разграничения их компетенций и установления подчинительных связей;

- разработка и внедрение коммуникационной модели взаимодействия финансово-контрольных структур в условиях цифровой и интеллектуальной экономики;

- развитие трудового потенциала государственных служащих финансового сектора посредством внедрения IT-компетенций; 
- разработка и использование модели комплексного государственного аудита в рамках реализации целей Стратегии развития Счетной палаты РФ.

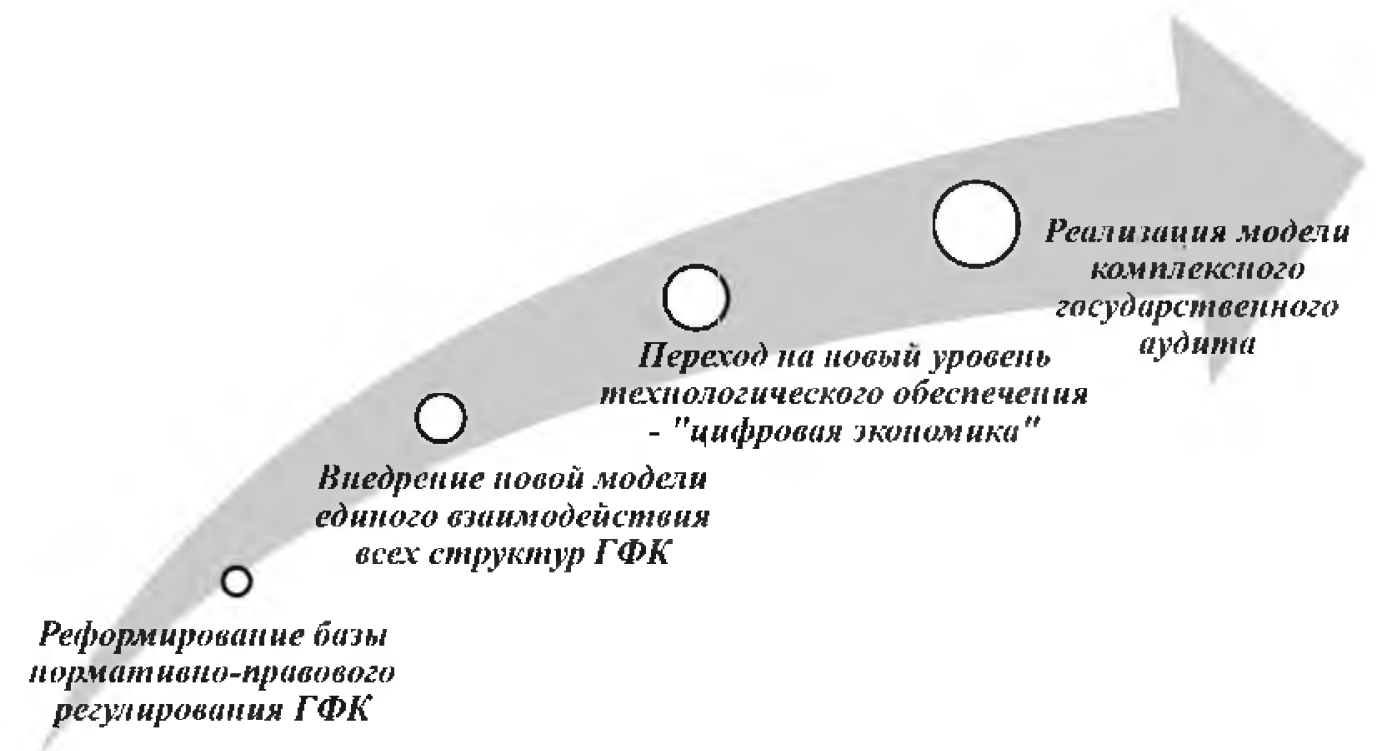

Рис. 3. Вектор развития отечественной системы ГФК в среднесрочной перспективе

Реформирование законодательства в части нормативно-правового регулирования деятельности органов ГФК осуществляется по следующим позициям (рис. 4).

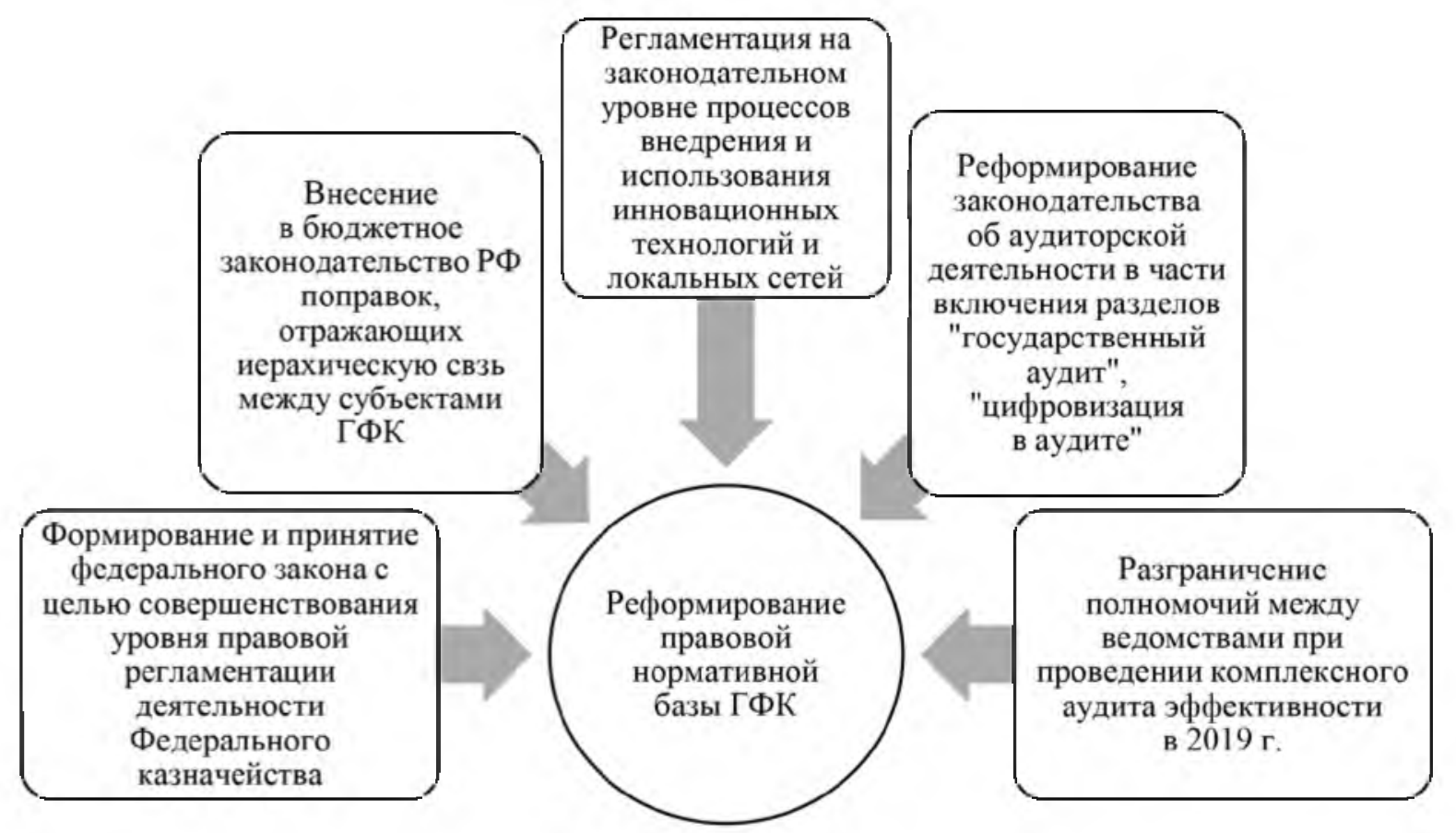

Рис. 4. Реформирование нормативно-правовой базы фунгционирования органов государственного финансового контроля 
Данные мероприятия ориентированы на реформирование федерального законодательства и необходимы для построения комплексной правовой основы деятельности органов ГФК в условиях цифровой экономики. Первостепенность их осуществления отвечает требованиям правового государства с позиции правового обеспечения эффективной деятельности государственных структур в системе исполнительной власти.

Построение рационального механизма функционирования органов ГФК в стране невозможно без соответствующего функционального обеспечения. В исследовательских работах встречаются различные варианты построения моделей создания единой системы ГФК при последовательном взаимодействии ее субъектов. Так, один из наиболее оптимальных подходов к формированию подобной структуры описан в статье заместителя руководителя Федерального казначейства Э. А. Исаева [2], где детально представлена модель осуществления государственного финансового контроля на федеральном уровне. Автор предлагает решить проблему отсутствия единства деятельности органов ГФК путем внедрения системы «вертикального контроля», базирующейся на риск-ориентированном подходе, снижении контрольных нагрузок и организации обратной связи.

Безусловно, данная модель достаточно обоснована с практической точки зрения и не противоречит реальным условиям сферы ГФК РФ, т. е. ее реализация с большой вероятностью решит многие организационные и экономические проблемы исследуемой области [2]. Однако в ней не предусмотрена возможность полноценного коммуникационного обеспечения субъектов системы ГФК, что повышает риск возникновения информационных сбоев при ее реализации. Поэтому считаем возможным предложить усовершенствованную модель взаимодействия государственных финансовых структур, построенную на основе горизонтальных информационных коммуникационных связей с учетом иерархии, предложенной Э. А. Исаевым (рис. 5).

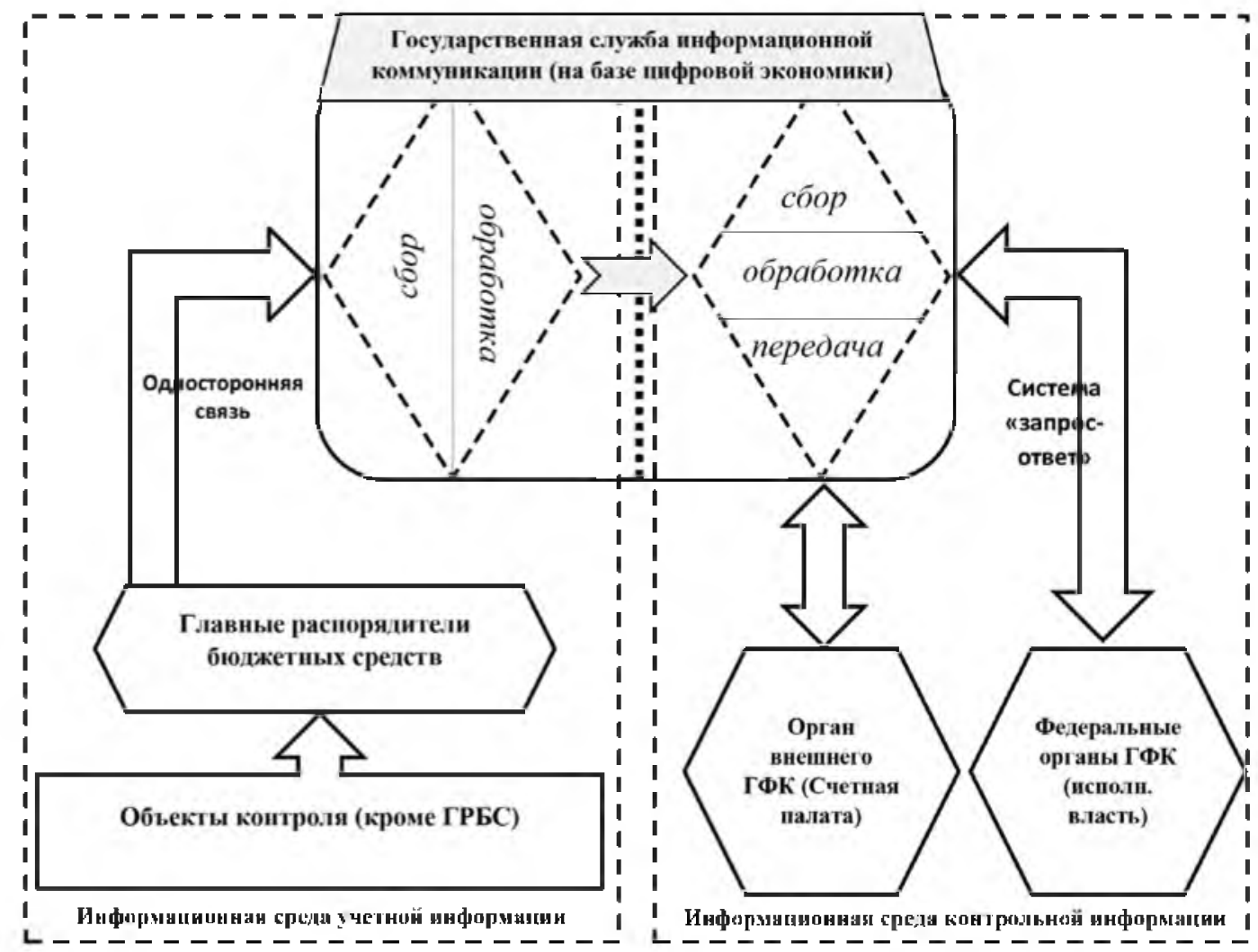

Рис.5. Модель горизонтальной информационной коммуникации субъектов ГФК 
Для функционирования предложенной модели должна быть создана специализированная служба информационного обеспечения государственного сектора - Государственная служба информационной коммуникации (далее - ГСИК). Техническое обеспечение функционирования этого подразделения возможно осуществить путем заказа соответствующего программного комплекса на официальном аукционе.

Данная модель строго ориентирована на коммуникационное взаимодействие органов ГФК на юридической основе, что снижет риск экономической взаимозависимости, обеспечивает правовую автономность существования ГСИК и одновременно «прозрачность» в деятельности суб́ъектов ГФК.

Преимуществом данной модели является создание двух информационных полей, одно из которых имеет только одностороннюю связь и предназначено для сбора данных (Центр организации сбора информации - ЦОСИ СЦИК), второе - непосредственно для свободного информационного взаимодействия органов ГФК в пределах их профессиональных интересов (Главный организатор коммуникационной связи контрольных органов - ГОКС КО СЦИК). Следует отметить, что любая двусторонняя связь между суб̋ъектами системы ГФК в рамках данной модели подразумевает использование коммуникационных каналов ГСИК для обеспечения профессиональной обработки данных в цифровых базах и их последующей регистрации.

Помимо этого, представленная модель обеспечит решение следующих задач:

1) установление возможности получения необходимой информации органами ГФК в короткие сроки;

2) минимизация рисков совершения нарушений субъъектами бюджетных отношений в части исполнения бюджетов;

3) возможность осуществления текущего контроля органами ГФК посредством доступности необходимой информации;

4) обеспечение прозрачности деятельности органов внешнего и внутреннего ГФК;

5) создание мощной информационной службы на более высоком уровне ее организации и реализации (внедрение цифровой экономики на макроуровне).

Вопросы экономического и методологического характера взаимосвязаны, и их решение напрямую зависит от эффективности выбранной государственными органами модели реформирования ГФК РФ.

Заключение / Conclusion. Таким образом, имеющиеся недостатки в правовом, организационном, методическом и экономическом обеспечении деятельности органов ГФК требуют применения комплексного научно-обоснованного подхода к разработке и реализации мероприятий по их устранению. Предложенная модель Государственной службы информационной коммуникации, предусматривающая рациональное взаимодействие финансовых контрольных органов РФ, позволит решить проблему возникновения противоречий и дублирований используемой информации, снизить организационные риски и повысить эффективность функционирования всей системы государственного финансового контроля в стране.

\section{ЛИТЕРАТУРА И ИНТЕРНЕТ-РЕСУРСЫ}

1. Акиндинова Н. В., Чернявский А. В., Авдеева Д. А. Результативность бюджетных расходов в России и странах ОЭРС // Вопросы экономики. 2017. № 2. С. 30-61.

2. Исаев Э. А. Подходы к формированию государственного финансового контроля в Российской Федерации // Финансовый контроль. 2018. № 9. С. 42-45.

3. Шевченко П. С. Развитие внешнего государственного финансового контроля в условиях модернизации бюджетного процесса // Творчество молодых ученых. 2017. С. 168-172.

4. Отчет о работе Счетной палаты Российской Федерации в 2017 году. [Электронный ресурс]. Доступ из справ.-правовой системы «КонсультантПлюс». URL: www.ach.gov.ru/ (дата обращения: 11.10.2018).

5. Федеральное Казначейство РФ: [Электронный ресурс]. Доступ из справ.-правовой системы «КонсультантПлюс». URL: www.roskazna.ru/ (дата обращения: 10.10.2018). 


\section{REFERENCES AND INTERNET RESOURCES}

1. Akindinova N. V., Chernyavskiy A. V., Avdeyeva D. A. Rezultativnost byudzhetnykh raskhodov v Rossii i stranakh OERS (Efficiency of budget expenditures in Russia and the OECD countries) // Voprosy ekonomiki. 2017. № 2. S. 30-61.

2. Isayev E. A. Podkhody $\mathrm{k}$ formirovaniyu gosudarstvennogo finansovogo kontrolya v Rossiyskoy Federatsii (Approaches to the formation of state financial control in the Russian Federation) // Finansovyy control. 2018. № 9. S. 42-45.

3. Shevchenko P. S. Razvitiye vneshnego gosudarstvennogo finansovogo kontrolya v usloviyakh modernizatsii byudzhetnogo protsessa (Development of external state financial control in the context of modernization of the budget process) // Tvorchestvo molodykh uchenyh. 2017. S. 168-172.

4. Otchet o rabote Schetnoy palaty Rossiyskoy Federatsii v 2017 godu (Report on the work of the accounts chamber of the Russian Federation in 2017) [Elektronnyy resurs]. Dostup iz sprav.-pravovoy sistemy «Konsultant-plyus». URL: www.ach.gov.ru/ (data obrashcheniya: 11.10.2018).

5. Federalnoye Kaznacheystvo RF (Federal Treasury of the Russian Federation) [Elektronnyy resurs]. Dostup iz sprav.-pravovoy sistemy «Konsultant-plyus». URL: www.roskazna.ru/ (data obrashcheniya: 10.10.2018).

\section{СВЕДЕНИЯ ОБ АВТОРАХ}

Бабаева Айида Эдуардовна, студентка 1 курса магистратуры, направления подготовки 38.04.01 Экономика, магистерской программы «Аудит и финансовый консалтинг», Института экономики и управления ФГАОУ ВО «СКФУ». E-mail: ajida.babaeva $a$ mail.ru

Тер-Григорьянц Анна Александровна, доктор экономических наук, профессор кафедры бухгалтерского учета, анализа и аудита Института экономики и управления ФГАОУ ВО «СКФУ». E-mail: ann_ter $a$ mail.ru

\section{INFORMATION ABOUT THE AUTHORS}

Ayida Babaeva, student 1st year of magistracy, areas of training 38.04.01 Economics, master's program «Audit and Financial Consulting», Institute of Economics and Management FSAEI HE «NCFU». E-mail: ajida. babaeva@mail.ru

Anna Ter-Grigoryants, Doctor of Economics, Professor, Department of accounting, analysis and audit, Institute of Economics and management, «NCFU». E-mail: ann_ter@mail.ru 